University of Nebraska - Lincoln

DigitalCommons@University of Nebraska - Lincoln

Faculty Publications: Department of Teaching, Department of Teaching, Learning and Teacher Learning and Teacher Education

Education

May 2006

\title{
Identities in the Making: Realized In-Between Self and Other
}

Margaret A. Macintyre Latta

University of Nebraska-Lincoln, Margaret.Macintyre.Latta@ubc.ca

Lori Olafson

University of Nevada, Las Vegas

Follow this and additional works at: https://digitalcommons.unl.edu/teachlearnfacpub

Part of the Teacher Education and Professional Development Commons

Macintyre Latta, Margaret A. and Olafson, Lori , "Identities in the Making: Realized In-Between Self and Other" (2006). Faculty Publications: Department of Teaching, Learning and Teacher Education. 30. https://digitalcommons.unl.edu/teachlearnfacpub/30

This Article is brought to you for free and open access by the Department of Teaching, Learning and Teacher Education at DigitalCommons@University of Nebraska - Lincoln. It has been accepted for inclusion in Faculty Publications: Department of Teaching, Learning and Teacher Education by an authorized administrator of DigitalCommons@University of Nebraska - Lincoln. 


\title{
Identities in the Making: Realized In-Between Self and Other
}

\author{
Margaret Macintyre Latta, University of Nebraska-Lincoln \\ Lori Olafson, University of Nevada, Las Vegas (Corresponding author)
}

\begin{abstract}
A middle school is a complex setting in which to develop a sense of self. The following accounts of three young women reveal ways that identity is confronted, offering insights for all learners. The intent is to show how prospective and practicing teachers can gain greater access to fostering identities in the making. The language of Bakhtin gives expression to the necessary teaching and learning conditions for students to look at the sense and selves being made on a continual basis. We conclude that valuing and validating identities in the making require that learning spaces be created, sustained, and nurtured as living, evolving encounters for negotiating ideas, making connections, and seeing possibilities, gaining insights into self and other. Educators must appreciate the student risking of self entailed in such learning encounters. Just as greater self-understanding should be at the core of all learning, and must be known in order to foster such understandings in others, so the tradition of self-study research needs to be at the core of teacher education programs.
\end{abstract}

Greene (1978) describes how discovery is taken out of learning when "the self as participant, as inquirer, as creator of meanings has been obliterated" (p. 12). The idea of an obliterated self aptly describes the schooling experiences of middle-school girls who describe how schoolwork requires negotiating ways through the quagmire of due dates, late penalties, grading criteria, routines, and rules. These experiences are not about negotiating ways through subject matter, playing with ideas, delving into complexity, or encountering difficulties through adapting, changing, and creating meaning. Students do interpret what is of value in schools, and they are validated through their responsive actions. The young women whose stories are told here do grapple seriously with feelings of being valued and validated.

Adolescence is often a particularly traumatic time for girls as they negotiate key questions of identity (Brumberg, 1997; Harper, 1997; Pipher, 1994). During our time researching and teaching in middle schools, we found the voices of adolescent girls 
echoing this fragile and vulnerable sense of self. Although pursuing different phenomena, we were amazed to discover similar themes arising from our work. One study, "Belonging to Learning" (Macintyre Latta, 2001), explored how students actively structure what is encountered in a school deliberately attempting to attend to learning processes, infusing arts-making processes throughout the curricula. Based on classroom observations, artifacts representing student and teacher thinking, and ongoing interviews with 26 students over a 2 -year period, more investment in learning was experienced when students were engaged in learning experiences through creating, making, adapting, and changing meaning. Data consisted of ongoing interviews with all participants, student work/artifacts, teacher work/artifacts, and classroom observations. Findings arising from that study are more extensively analyzed in Macintyre Latta (2001). The focus of this study became a search for ways to portray the differences arising out of attending to learning processes for learners, learning, teachers, and teaching, documenting the consequences.

A second study, "Competing Regimes of Truth in the Lives of Adolescent Girls," involved 10 girls in grades 7 and 8 who attended two traditional middle schools. Data collection over 2 years included classroom observations, ongoing interviews, and artifacts representing student responses to learning. Participants were identified as atrisk for dropping out of school despite academic indicators suggesting the capacity for school success. Olafson (in press) provides more extensive analysis of the findings arising from this inquiry. These participants reported rarely becoming connected to their learning and were in the process of fading out of school (Sefa Dei, Massuca, McIsaac, $\&$ Zine, 1997). Data arising from both studies point to the need for deliberate concern toward adolescents' needs for interconnecting learning and personal commitment.

These two studies used a reflexive approach (Alvesson \& Skoldberg, 2000) to data collection and analysis, operating both inductively and deductively to address the interface between the empirical data collected (through ongoing content analyses of student/teacher artifacts, classroom observations, and interviews), its interpretations, and the research literature that situated the study. Through dialogue and responsive interchange, data sources were examined. These included participant narrative statements, researcher field notes, teacher lesson plans, associated resources, and audiotaped interviews. To examine the intersections between the two studies, a case-study approach (Creswell, 2002) at two levels was employed with each study constituting a case. First, the researchers analyzed data from each case for common themes and differences. Second, to determine the intersections, a cross-case and group analysis was conducted. Data analysis took place in three phases. Phase I focused on the individual cases, looking for emergent features, blocking and labeling thematically all data, to ascertain similarities and differences for learners, learning, teachers, and teaching. Phase II entailed a cross-case analysis identifying themes common to both cases and also significant differences between cases. Phase III focused on finding an organizing framework depicting the intersections between the two studies. As we juxtaposed participants' narratives, we discovered similarities and differences across common themes, including painful schooling stories, sensitivity to spectacle and display, lack of connection, and a lost sense of self. 
The accounts of three young women in particular are striking; Andrea and Susan (both participants in "Belonging to Learning") and Alicia (participant in "Competing Regimes of Truth in the Lives of Adolescent Girls") all wrestle with their sense of self at school, amid what Kelly (1997) calls the contextual density of schooling. We characterize these young women as bright, articulate, and confident, with above-average academic capabilities as indicated by previous school records and pre-recorded standardized tests. We present their accounts to vividly illustrate that middle schools are a complex venue within which to develop a sense of self. We see the insights these young women's voices offer as speaking for other, less articulate students, male and female, whom we both met in our respective studies that looked at the fragile nature of identity negotiation and its integral role and place in learning. Prospective and practicing teachers may be able to use these accounts to gain greater access to student identitiesin-the-making and to teachers' power and responsibility to create learning contexts that value and validate identities. As teacher educators, we found that these accounts served as a catalyst to self-study, heightening the awareness and responsibility we take toward creating teacher education programs that foster teacher identities-in-the-making so they can return these experiences to their own students.

\section{Students' Accounts of Learning}

\section{Andrea}

Andrea talks about how she likes to think about her schoolwork when she describes a writing project:

Most of my work seems unfinished, but that is part of my creativity. I love it when my work shows my thinking. I like the ongoing feedback from teachers. I like thinking about imaginative possibilities. The idea for the story that I am writing comes from a book I read. I enjoy this book because it reminds me of a watercolor painting - the story line is very fluid. I want my story to have that feel. The story takes place 100 years ago in a castle. The idea of a castle intrigues me with the images that come to my mind. I am taking this castle image as a setting for the story that I am writing and developing a character that has ghosts for friends. Historical figures will inform these friends. I intend to use facts about their lives within the story. I am excited about how these friends will interact. I am really figuring out my writing as I go along. It is hard for me to write a plan in advance. I realize inbetween. (Interview \#1, January 20, 1998)

Andrea is keenly aware of a space that positions her between self and subject matter. There is belongingness to her learning that cannot be dismissed. In pursuing why she finds this in-between space so vital, Andrea is able to explain that she cares about the characters she is inventing, that the story line intrigues her and captures her imagination, and that she likes the involvement she feels as she creates her story. When we asked if Andrea has experienced learning in ways that thwarted access to this in-between space, she answered as follows: 
This is the first class I have felt that it is normal to work this way. I often think about assignments a lot but I would not have talked about my process like I am now. I am pretty sure that most teachers were only interested in seeing the final stuff I produced. Usually I got "excellent" written on stuff but I am not so sure the thoughts were really read. At least I did not feel teachers were sincerely interested in my ideas, my writing. (Interview \#1, January 20, 1998)

The reference to sincerity speaks to the self that Andrea tentatively exposes through her thinking. She clarifies that she was more apt to conceal this in school in the past:

Lots of times I would answer questions from a textbook and really try to put things in my own words, but I decided that it was stupid because the teacher mostly just cruised by me and glanced to make sure I had answered all the questions, marking my paper with a happy face to indicate it was complete. (Interview \#1, January 20, 1998)

Andrea is new to the middle school she is attending. The decision to attend this school was made deliberately by her and her parents. The philosophy of this particular middle school, with its focus on creative processes across all disciplines, attracted them. Andrea's mother explained her reasoning:

I have seen my daughter frantic to fit creativity into her day. It is a physical need within her. For the first time I see that need being met at school. (Interview \#1, January 20, 1998)

Andrea knows the importance of creativity to her sense of self and who she is becoming. She seizes the opportunity to pursue this in her daily schoolwork.

\section{Susan}

Susan is a classmate of Andrea's who also seizes the opportunity to explore who she is and who she is becoming through her schoolwork. The following excerpt is from a written response accompanying a cultural imagery assignment completed for her humanities class:

My work is called "Groups Apart." Why is this? How could groups be apart? Quite easily, I believe. In going together we have made ourselves in other groups instead of a whole. The blue set of triangles is the obvious leader group, perfect, perhaps, but only in their own idea of perfection. The other groups are a part, yellow, pink, and some greens. They might want to be like the blues, but are torn by individuality, or not liking the blue's ways. The blues shun the other colors. They want the other colors to be like them, but the others cannot. The blues will not accept the truth. The blues create a generic for everyone to follow; the children must all be the same. Despite the blue's ways, all the colors still fit together, edging in the same direction, either chaos or wonder. The brilliant citrus colors I chose represent that each of the groups is different in its own way, yet is also the same in some ways. If only people would accept that and not try to change it. I find this repeating many times in our culture. When Englishmen came to Canada, they civilized the natives, taking them to schools and insisting 
on their superior ways. In Western society now, we go to Africa and do the same thing but in a gentler approach. In our school we repeat this. Why must we be judged on our outer looks, or our brains, or something else? Why can't we just be accepted for who we truly are? Those are questions I cannot answer myself, but can only wonder. Is it because we are afraid and simply cower in a safety we have created for ourselves? (Artifact \#12, September 23, 1998)

Susan is provided with an opportunity to question the role of others and otherness in human relationships. She and her classmates spend time examining the notion of culture from a variety of perspectives in their humanities class. Many class discussions arising from a novel study (Cormier, 1992) elicited much debate over values, beliefs, and judgements of right versus wrong. Susan and her classmates are expected to find and take up a particular cultural concept that each feels matters and needs to be addressed. They are to synthesize their thinking on this aspect of culture by portraying it in both illustrative and written form. Susan invests herself in the visual and written texts created. She gives consideration throughout the process to colors, lines, shapes, and textures, and how parts are connected, and also to the overall impact of the statement created. Susan's written comments reveal an emotional commitment that intimately connects her with her work, and she questions herself throughout the process. She deliberates and responds accordingly. As Susan thinks about her imagery, she confronts her own prejudices, fears, and limitations in her writing. She creates a personal account of acceptance by peers and notes parallel accounts throughout history. For her, response entails responsibility; the task itself demands this. Susan embraces the uncertainties of the task, placing herself in the middle between self and other, as both catalyst and sounding board. The task assumes this fundamental reciprocity between self and other. Susan has the opportunity to make the task personal, is given time and guidance to be attentive to specific qualities and relations, and is encouraged to attend to the thinking process. Thus the learning task becomes a medium, a way towards learning rather than an end in itself, engaging rather than disconnected and removed.

\section{Alicia}

Alicia has been identified as an at-risk learner. Although at risk of dropping out of school, the compilation of test scores and paper-trail indicators portrays a student with a bright educational future. The contradiction is disturbing, and Alicia herself is keenly aware of this contradiction:

I had an identity crisis because I just didn't know who I was. It's hard to maintain an identity when the push is to be alike. Everybody wants to be the same. But that's stupid because not everybody thinks the same, not everybody acts the same. I feel like an outsider on the inside, because I see myself as an individual. The other kids are more concerned with how their friends see them, but I value intelligence unlike the other kids here. I guess you just have to figure out who you are as a person and it's hard to do that at school, especially when the teachers treat you all alike and all the work is the same. Like I hate the stupid worksheets in Math - if there isn't any 
thinking involved, it doesn't appeal to me. I like it when there isn't only one right answer. The lessons are so boring. I don't feel like I have to soak up the information that I'm getting from her lecturing. When she talks, I cannot listen. It just goes in one ear and out the other. Sometimes she talks so much we don't even have any time to do the work. Everything is from the textbook. I don't even have to be there to learn her lessons. (Interview, December 3, 1998)

Alicia admits a felt sense of difference, saying that she feels like an outsider on the inside. She recognizes that she is "other," yet she refuses to mimic her classmates' actions and appearance to become more popular, in contrast to the majority of adolescent girls who rate being popular and well-liked as more important than being competent or independent (American Association of University Women, 1992). Alicia finds it difficult, if not impossible, to assert her difference (her individuality) within the context of schooling, where the myth of sameness abounds. The tensions that she experiences, between the desire to be different and the push to be the same, lead Alicia to seek a sense of her social self outside of school. She chooses to identify with a peer group whose commonality appears to be indifference to the institution of schooling. Socializing with "street kids," she finds the freedom to be different from the identity imposed by her peers at school. At school, she is known as a "Druggie," although she adamantly rejects this label. She classifies herself as an "independent" because of her non-participation in the social games of her peers; she is indeed an outsider on the inside. On the street, however, her sense of self is honored and she feels that she belongs. Contrasting her school peers to her street peers, Alicia comments on how peer relationships affect sense of self:

Last year the peer thing was pretty bad - nobody liked me, everybody had something against me and I was so self-conscious. Now most of my friends do not go to school; they are on the street. They are older, more mature, and I can talk to them. I can trust them and say, "Hey, I have a problem," and they will not spread it around or gossip. They just understand better than the kids at school. (Summary Transcript, May 28, 1998)

Alicia recognizes that most of her schoolwork obliterates her self as a participant, as an inquirer and as a creator of meanings, and thus fails to provide opportunities for discovery in learning. All too often, Alicia is on the receiving end of learning experiences within a monolithic curriculum. By virtue of her grade level, Alicia is assumed to have similar, if not identical, needs to her peers. She is positioned by learning tasks within this kind of curriculum as if she has a fixed and unified subject position that is indistinguishable from those of her classmates. However, Alicia wants to be challenged and wants to engage in tasks that involve creating, making, adapting, changing, and building meaning. She insists that she loves learning, but is rarely given meaningful tasks. Disconnected from her learning and faced with boring, mind-numbing tasks, such as the "stupid" work sheets in Math, Alicia, at times, attempts to make the tasks relevant. When given the opportunity to choose her own writing topic in language arts, Alicia adopts a philosophical approach, writing a collection of essays that represent what she calls her "truths." In her conclusion, Alicia writes about the 
"unwanted one who is placed in a black box: a realm of ignorance; a shield from individuality; an outcast; banding creativity, controller of feelings, shunning emotion" (Artifact 14, June 1998). Clearly, she is personally invested in this writing, but far removed from school and schooling.

\section{Positioned by Peers, Teachers, and Tasks}

Ruiz (1998) maintains that the social system that peers create for themselves at school is complex and virtually unknown to the adults in the building. This system has a tremendous impact on how Andrea, Susan, and Alicia see themselves and others. We observed hierarchical social groups operating in our school sites, reflecting what Finders (1997) calls the power of the peer dynamic: students affixed labels to themselves and to others that determined social acceptability. Andrea, Alicia, and Susan question these terms of inclusion and exclusion dictated by their peers and, at times, openly contest the meanings assigned to their lives. Alicia writes

We are scared to be different, yet I think that we are trapped by our differences. We label other people much too easily. By creating little communities (e.g., Skids, Skaters, Preps, Burnouts), we are only dividing ourselves. (Artifact 11, June 1998)

Andrea, Susan, and Alicia acknowledge the difficulty of living within and going against the grain of this social system created by their peers. In Andrea' and Susan's class, though, students are given the opportunity to explore these issues. In this classroom a diversity of responses is expected and respected by the teacher and, in turn, the students, because everyone's work is displayed, honored, and discussed by the class as a whole. The impact of multiple ideas and perspectives is brought to the forefront and a forum is created that encourages analysis, criticism, and questioning. An open-endedness permeates this forum as well, as the work is taken up in discussion as it progresses and may be blurred with curiously unfinished or incomplete thoughts.

Alicia's teacher is supportive and encouraging as Alicia struggles with her sense of self in the classroom. Alicia often seeks out her teacher to discuss privately her felt sense of difference. Within the messy reality of the classroom, however, the teacher finds it difficult to create a space that honors difference and recreates discovery in learning. She, too, is constrained by a school context that assumes all students in a particular grade level require precisely the same learning experiences. Mastery learning of required subject matter takes precedence over considering topics that might be related to important issues in the lives of the adolescents in the classroom. The school context constrains discovery for both teacher and student.

Andrea and Susan's teacher searches for ways to draw them into the depth and complexity of subject matter, positioning them to be receptive to sensory qualities and relations of self and subject matter on an ongoing basis. The teacher develops a variety of non-directive teaching practices that support non-linear as well as linear learning. Divergent learning responses are encouraged, allowing students some choice in the 
way they choose to engage with subject matter. A spirit of inquiry is created in which room for experimentation and invention of meaning is fostered. Imaginative thought, requiring speculation and conjecturing about possibilities evolves. Such conjecture creates a space for students to participate deliberately in learning more about others and, in turn, themselves.

\section{A Black Box and an In-Between Space}

How Andrea, Susan, and Alicia were positioned to take up their schoolwork resulted in Alicia's metaphor of a "black box" or Andrea's metaphor of an "in-between space." The metaphor of a black box is confined, private, and offers refuge. The self hides in the black box, reluctant to share personal understandings or experiences, careful not to reveal self, purposefully excluding self from subject matter. The metaphor of an inbetween space takes an organic, dynamic shape. Interaction is key, demanding participatory thinking realized through the act of sense-making. The voices of Andrea and Susan reveal an animated or essential part of self, evidenced in passion and commitment that connects them to their learning. These are noticeably absent in Alicia's account. We grapple with how such relationships are structured and encountered to evoke the wonder, participation, and belongingness portrayed by Andrea and Susan.

\section{Bakhtin's Language}

The conditions and assumptions that cause learners to enter completely into learning encounters lead us to the thinking of Bakhtin (1993), who conceived a fundamental ontology that gives expression to the encounter between subject and world. Bakhtin emphasizes the connectedness of the act of creating meaning that takes life as a movement of thought. It is this movement of thought, the creation of meaning, negotiated between self and other that we see and hear in the voices of Andrea and Susan that holds so much potential for identities in the making.

In Toward A Philosophy of the Act, Bakhtin (1993) emphasizes the uniqueness and singularity of acts of creating personal meaning. From within the act or deed, participatory thinking orients individuals. This focus on the act as it is happening makes it necessary to see the act not as a given contemplated at a distance (the metaphor of the "black box") but from within, taking into account the givenness, moment by moment (the metaphor of an "in-between space"). "And all these moments, which make up the event in its totality, are present to him [or her] as something given and as something to be achieved conjointly" (Bakhtin, 1993, p. 30). The simultaneous awareness of both something given and something yet-to-be-achieved is crucial to the intent of Bakhtin's attempt to describe the world in which the actor becomes aware of the catching of self in the act. He is clear that it is not aimed at describing the world produced by that act. It is through Bakhtin's thinking that we realize that Andrea's and Susan's accounts explore the concrete not simply as a step toward something else, but rather, concomitantly, as a knowing of the present and how to proceed meaningfully. 
Bakhtin's (1993) insistence on attending to the act of creating meaning assumes that one must enter as a creator into such acts. Thus he grounds the creating act in the unique human being, located spatially and temporally in the phenomenology of selfother relations. Bakhtin portrays such entering into self-other relations as occurring through events to be lived out, enacted, or achieved.

In which the moments of what-is-given, and what-is-to-be-achieved, of what is and what ought to be, of being and value, are inseparable. All these abstract categories are here constituent moments of a certain living, concrete, and palpable (intuitable) once-occurrent whole - an event. (Bakhtin, 1993, p. 32)

Thus the creator finds herself in the in-between space posed by Andrea. Bakhtin (1990) further describes such a space as the problem of content, material, and form: content being what work is about, material being the concrete and abstract matter from which work is constructed, and form being the relationships in work between and among self, content, and materials (Bakhtin, 1990, pp. 257-325). The problem of content, material, and form does not require a problem-solver so much as the capacity Bakhtin (1993) terms "aesthetic seeing." Aesthetic seeing is characterized as a releasing or opening of one's self to the present, an immersion in immediacy. It offers accounts of experienced space, time, body, and human relations as they are lived. There is an ebb and flow; a rhythmic quality to time that is not determined by external timetables. It requires listening, responding, and openness in what is heard and what is said. Such engagement thrives on unforeseen possibilities. Such a space places self clearly in the midst, as catalyst and sounding board. Bakhtin (1993, p. 61) explains that "what constitutes this center is the human being: everything in this world acquires significance, meaning, and value only in correlation with man [sic] - as that which is human."

Thus the act of creating is oriented through actual experiencing, demanding interconnections between self and other. Bakhtin (1993) further clarifies

Content, after all, does not fall into my head like a meteor from another world, continuing to exist there as a self-enclosed and impervious fragment, as something that is not woven into the unitary fabric of my emotional-volitional, my living and effective, thinking-experiencing, in the capacity of an essential moment in that thinkingexperiencing. (p. 33)

Content comes to be understood within the act of participation in events themselves, thus characterized as unique, lived, embodied, and contextual, wholly dependent on self-involvement. Aesthetic seeing searches for the potential in materials to provide direction, both shaping and limiting inquiry. The connections fostered are a catalyst to insights, giving the inquiry meaning and life. Thus Bakhtin describes form and material as "the form of content, but a form which is realized in the material - is attached to the material, as it were" (1990, p. 303). Form is understood as the expression of activity, and form very much includes "its creator within itself" (pp. 315-316). Bakhtin's description of the internally active human being as creator entering form through seeing, hearing, evaluating, connecting, and selecting is represented in the thinking of Andrea and Susan. "Form ceases to be outside us as perceived and cognitively ordered material; it becomes an expression of a value-related activity that penetrates content and transforms 
it" (p. 305). Thus the process is inseparable from the product. Bakhtin (1993, p. 19) claims that this requires that participants "know how not to detach their performed act from its product, but, rather how to relate both of them to the unity and unique context of life and seek to determine them in that context as an indivisible unity."

Bakhtin (1990) suggests a language that expresses the movement necessary to grapple in-between self, content, material, and form, fusing process and product into an interdependent, ongoing unity. Within this indivisible unity, Bakhtin introduces the language of answerability, outsideness, and unfinalizability for describing involvement in the creating act. He portrays answerability arising out of a fundamental reciprocity between self and content, continually relating to personal understandings and values. Bakhtin explains how this is not derived from a mechanical relationship of parts to whole. "The parts of such a whole are contiguous and touch each other, but in themselves they remain alien to each other" (1990, p. 1). Rather, answerability is dependent on personal involvement. Such involvement necessitates taking "an axiological stand in every moment of one's life or to position oneself with respect to values" (1990, pp. 87-88). Bakhtin further explains that he sees this living and moving "not in a vacuum, but in an intense axiological atmosphere of responsible, answerable, indetermination" (1990, p. 275). Bakhtin's claim is that answerability is not a given, but rather is seen as a task to engage in and with, through participation in the creating process. An emotional commitment and involvement expressing what is particular and irreplaceable in each situated individual comes forth. For example, through participation Susan questions. By deliberating and doing, she becomes an answerer. The subject matter starts to matter to her. This investment of self leads to deeper involvement and greater care. It is impossible for Bakhtin to imagine living in a world where all content is imposed. In that world, answerability is impossible. "In that world I am unnecessary, I am essentially and fundamentally non-existent in it" (1990, p. 9).

Answerability is difficult in Alicia's classroom, where content is apt to be imposed. As an individual learner, she is "nonexistent" because the majority of the assigned tasks position her as one of many nameless, faceless, voiceless students in the classroom. In contrast, Susan's account portrays how one's distinctiveness from others can be a catalyst to enlarged understandings and diverse thinking. Bakhtin (1986) explains how outsideness makes this possible. Outsideness speaks to his interpretation of the self as a fully embodied self, a self that is constituted interdependently with the other. For Susan, outsideness is experienced through an interdependence realized at boundaries where her understandings come up against or meet another. Each needs the other. A self-consciousness takes hold that is not ground in a solitary consciousness, but rather a developing greater consciousness of other, others, and in turn, self. Thus, neither self nor other are bound entities; they intermingle in a body-world relationship yielding an outsideness, belonging as much to the other as self. It is not that Alicia does not speak of her distinctiveness from others, but the outsideness experienced by Alicia is not conducive to greater productivity and creativity. Susan's thinking is considered work in progress, connected to previous thinking and moving towards new thinking. Alicia's thinking is not valued in the same ways, with little opportunity for independent thought and little possibility for transformation. Susan makes judgements de- 
rived largely on what surfaces during process; thus meanings are tentative. This is the nature of Bakhtin's (1990) notion of unfinalizabilty (pp. 121-132). The interaction of self and other is ongoing and ultimately unfinalizable. There is openness to unasked for and unpredictable learnings. Change and transformation are always possible.

\section{Conclusions}

Bakhtin's (1993) portrayal of this space in-between self and other positions the learner to encounter the confluence and flux of answerability, outsideness, and unfinalizability informing each other on a continual basis. Perhaps these restore a necessary spirit integral to teaching and learning that demands presence, attaching participants to their learning. Andrea and Susan's accounts tell us such relationships established and nurtured seem to endure; significance is retained. Gadamer (1992) reiterates this insight, claiming she "comes to belong more fully by recognizing [herself] more profoundly in it" (p. 133). Transformed subjectivities seem to emerge from participating in the movement of thinking, thereby taking something away from the process. Thus the centrality of the other is constitutive of the self. In contrast, as Alicia's account tells us, an obliterated self is severed from learning, detached from the circumstances in which learning develops. Bakhtin (1993) provides a language giving expression to the in-between space necessary toward formulating and reformulating identities in the making. But such a space must be created, sustained, and nurtured as a living, evolving encounter for negotiating ideas, making connections, and seeing possibilities, gaining insights into self and other.

There is much potential, power, and responsibility implicit in valuing and validating identity formation within the teaching act. It is the teacher who holds the greatest potential to act as a catalyst or thwart attempts in this regard. Thus educators must be cognizant of this in their actions, creating the necessary conditions for identities-inthe-making. Educators must also appreciate the risking of selves integral to making, valuing, and validating identities-in-the-making. Concomitantly, educators need to address the risking of selves lost, subsumed, obliterated, when learning is imposed and identities-in-the-making are devalued and invalidated.

\section{Implications}

Neither of the studies discussed in this paper was originally conceived as a self-study. However, as we placed our individual studies within a larger context, we began to realize the implications for our work in our lives as teacher educators. This paper can be seen as collaborative activity that incorporates many of the aspects of self-study, including a focus on personal experience and practice (Loughran \& Russell, 2002; Zeichner, 1995, 2001), accepting responsibility for preparing teachers (Northfield, 1996), and considering ways to apply new knowledge to improving our teaching practices (Bullough \& Pinnegar, 2001; Samaras, 2002). 
We noted that classroom teachers are the catalysts for creating the conditions for valuing and validating identities in the making. The question that we must ask ourselves is "In the context of our own practices as teacher educators, how can we embody Bakhtin's (1990) notions of answerability, outsideness, and unfinalizability?" Implications for our practice include a willingness to change practices. As Feldman (2003, p. 27) notes, "self-study recognizes at least implicitly that to improve our teacher education practices we need to change our ways of being teacher educators." Prospective teachers must encounter answerability, outsideness, and unfinalizability throughout their studies. It is our responsibility as teacher educators to create such learning encounters and engage prospective teachers in continually negotiating between self and other. It is only through such negotiation that prospective teachers will gain greater cognizance of themselves as identities in the making and then be able to see and foster this in the students they will meet.

The accounts of Andrea, Susan, and Alicia provide concrete portrayals that tell us that always turning back on self is the catalyst for learning in all of us. These three individuals remind us why it matters, offering glimpses into the power of schooling impacting identity formation. We are compelled to return to Bakhtin (1990) and the language of answerability, outsideness, and unfinalizability as we turn our engagement toward self-studies of our own teacher education practices. We begin to revision our teacher education classrooms. Belonging to learning, as we have described, requires an environment where a spirit of inquiry abounds, where a diversity of responses is expected and respected, and where identity is recognized as in process rather than as fixed and unified subject positions. We have argued that, within these conditions, students in middle school may experience belonging to learning. Preservice teachers within our college classrooms must also experience belonging to learning if they are to enable this in their future teaching practices. Finding ways to create learning relationships through answerability, outsideness, and unfinalizability became the task at hand.

Answerability is impossible in a world where all content is imposed, says Bakhtin (1990). As teacher educators, we must seek ways for our students to become emotionally committed and involved with the content. An interdependence between answerability and personal involvement emerged as prospective teachers examined teaching and learning case narratives as a means to such participatory thinking. Understandings widened and deepened through attending to multiple perspectives on issues arising out of each case narrative. Outsideness is the capacity to fully attend to the other, reaching beyond the self as a means to greater self-understanding. Prospective teachers come to realize the value of the other in relation to self-understanding as teaching and learning case narratives opened into occasions to confront personal values, beliefs, and assumptions regarding learners and learning. Increasingly answerability and outsideness were seen as ongoing and unfinalizable. In our changing roles as teacher educators, we encourage our students to negotiate the acts of teaching and learning through adapting, building, and creating meaning in an ongoing reciprocal relationship between self and other. In so doing, we realized that we had to avoid perpetu- 
ating the notion that teacher education yields fully finished products in the form of beginning teachers. Learning to teach must embrace this process of becoming: a time of formation and transformation, of scrutiny into what one is doing, and who one can become. It is the tradition of self-study research that most vividly and powerfully encounters self. Turning back on self is the necessary turn that we have taken and that teacher education programs must make. Self-study has shown us that self-understanding is the long overdue return to the work of learning.

\section{References}

Alvesson, M. and Skoldberg, K. (2000). Reflexive methodology Sage, London.

American Association of University Women (1992). The AAUW report: How schools shortchange girls. Report by Wellesley College Center for Research on Women. American Association of University Women and National Education Association, Washington, DC.

Bakhtin, M. M. (1986). Speech genres and other late essays. University of Texas Press, Austin, TX.

Bakhtin, M. M. (1990). Art and answerability: Early philosophical essays. University of Texas Press, Austin, TX.

Bakhtin, M. M. (1993). Toward a philosophy of the act. University of Texas Press, Austin, TX.

Brumberg, J. (1997). The body project: An intimate history of American girls. Vintage, New York.

Bullough Jr., R. V. and Pinnegar, S. (2001). Guidelines for quality in autobiographical forms of self-study research. Educational Researcher 30:3, pp. 13-21.

Cormier, R. (1992). Tunes for bears to dance to. Delacorte, New York.

Creswell, J. W. (2002). Educational research: Planning, conducting, and evaluating quantitative and qualitative research. Merrill/Prentice Hall, Upper Saddle River, NJ.

Feldman, A. (2003). Validity and quality in self-study. Educational Researcher 32:3, pp. 26-28.

Finders, M. (1997). Just girls: Hidden literacies and life in junior high. Teachers College Press, New York.

Gadamer, H. G. (1992) Truth and method. Continuum, New York.

Greene, M. (1978). Landscapes of learning. Teachers College Press, New York.

Harper, H. (1997). Disturbing identity and desire: Adolescent girls and wild words. In Todd, S. (ed.), Learning desire: Perspectives on pedagogy, culture, and the unsaid (pp. 141161). Routledge, New York.

Kelly, U. (1997). Schooling desire: Literacy, cultural politics, and pedagogy. Routledge, New York.

Loughran, J. and Russell, T. (Eds.) (2002). Improving teacher education practices through selfstudy. RoutledgeFalmer, London. 
Latta, M. Macintyre (2001). The possibilities of play in the classroom: On the power of aesthetic experience in teaching, learning, and researching. Peter Lang, New York.

Olafson, L. (2006). "It's just easier not to go to school": Adolescent girls and disengagement in middle schools. Peter Lang, New York.

Northfield, J. (1996, April). Quality and the self-study perspective on research. Paper presented at the meeting of the American Educational Research Association, New York. ED 397 034.

Pipher, M. (1994). Reviving Ophelia: Saving the selves of adolescent girls. Ballantine Books, New York.

Ruiz, R. (1998). Indiscipline or violence: The problem of bullying in school. Prospects 28:4, pp. 587-599.

Samaras, A. P. (2002). Self-study for teacher educators: Crafting a pedagogy for educational change. Peter Lang, New York.

Dei, G. Sefa, Massuca, J., McIsaac, E. and Zine, J. (1997). Reconstructing "drop-out": A critical ethnography of the dynamics of Black students' disengagement from school. University of Toronto Press, Toronto, Canada

Zeichner, K. (1995). Reflections of a teacher educator working for social change. In Russell, T. and Korthagen, F. (eds.), Teachers who teach teachers: Reflections on teacher education (pp. 11-24). Falmer, London.

Zeichner, K. (2001). Educational action research. In Reason, P. and Bradbury, H. (eds.), Handbook of action research (pp. 273-284). Sage, London. 